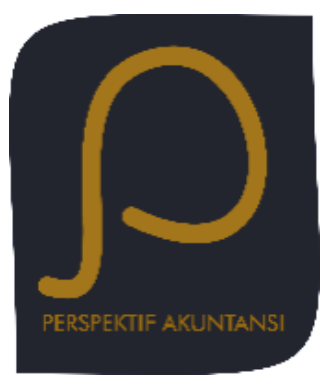

Perspektif Akuntansi

Volume 4 Nomor 1 (Februari 2021), hal. 1-12

ISSN: 2623-0194 (Print), 2623-0186 (Online)

Copyright(C) The Authors(s). All Rights Reserved

Center for Accounting Development and Research (CARD)

Fakultas Ekonomika dan Bisnis,

Universitas Kristen Satya Wacana

DOI: https://doi.org/10.24246/persi.vXiX.p1-12

http://ejournal.uksw.edu/persi

\title{
Aplikasi Capital Asset Pricing Model dalam Evaluasi Kelayakan Investasi Daerah
}

\author{
Harijono ${ }^{1}$ \\ Ari Budi Kristanto \\ Apriani Dorkas Rambu Atahau \\ Fakultas Ekonomika dan Bisnis, Universitas Kristen Satya Wacana
}

Received

15/04/2021

Revised

16/04/2021

Accepted

17/04/2021

\begin{abstract}
Regional autonomy encourages local governments to invest as a means of increasing regional economic growth. In order to evaluate regional investment decisions it is necessary to carry out a capital budgeting analysis. Capital Asset Pricing Model is a method of calculating the cost of capital in investment analysis which is widely used in the business world. This study aims to examine the CAPM application in regional investment decisions. By using secondary data from financial reports and hypothetical auditors' reports for the period 2012-2017, the results show that CAPM can be used in making regional investment decisions. Thus, the investment feasibility analysis of local governments can use CAPM because CAPM as an evaluation tool will provide the objectivity of the assessment necessary so that the investment decisions taken are correct
\end{abstract}

Keywords: capital budgeting, local government investment, CAPM, cost of capital

1 harijono@uksw.edu 


\begin{abstract}
Abstrak. Otonomi daerah mendorong pemerintah daerah untuk berinvestasi sebagai salah satu sarana meningkatkan pertumbuhan ekonomi daerah. Dalam rangka mengevaluasi keputusan investasi daerah perlu dilakukan analisis penganggaran modal. Capital Asset Pricing Model adalah metode perhitungan biaya modal dalam analisis investasi yang digunakan secara luas di dunia usaha. Penelitian ini bertujuan mengkaji aplikasi CAPM dalam keputusan investasi daerah. Dengan menggunakan data sekunder dari laporan keuangan dan laporan auditor selama periode 2012-2017, hasil penelitian menunjukkan bahwa CAPM dapat digunakan dalam pengambilan keputusan investasi daerah. Dengan demikian, analisis kelayakan investasi pemerintah daerah dapat menggunakan CAPM karena CAPM sebagai alat evaluasi akan memberikan objektifitas penilaian yang diperlukan agar keputusan investasi yang diambil menjadi tepat.
\end{abstract}

Kata kunci: penganggaran modal, investasi pemerintah daerah, CAPM, biaya modal

\title{
Pendahuluan
}

Meningkatnya persaingan dalam dunia usaha dan adanya tuntutan profesionalitas dalam tata-kelola Badan Usaha Milik Daerah menuntut manajemen untuk selalu sigap dalam menangkap peluang-peluang bisnis ke depan. Oleh karena itu dalam rangka menangkap peluang bisnis yang ada, mendorong pengembangan dan peningkatan kinerja Perusahaan Daerah, pemerintah daerah menerbitkan Peraturan Daerah yang mengatur tentang Penyertaan Modal Pemerintah Daerah pada Perusahaan Daerah. Oleh karena itu dalam rangka mengevaluasi keputusan investasi daerah yang berkonsekuensi pada penyuntikan modal perlu dilakukan investasi.

Sebagaimana diketahui, terdapat tiga kategori proyek pemerintah (Sinaga, 2018). Kategori pertama adalah jenis proyek yang secara keuangan tidak layak (financially not feasible) namun sangat diperlukan keberadaannya sehingga pengerjaan proyek ini didasarkan pada pertimbangan biaya-manfaat (cost benefit analysis) dan nilai tambah (multiplier effect) yang dihasilkan proyek tersebut. Pendanaan untuk proyek ini diperoleh dari Anggaran Pendapatan dan Negara (APBN) atau Anggaran Pendapatan Belanja Daerah (APBD). Kategori kedua adalah proyek yang pengadaannya merupakan tanggung jawab atau kewajiban pemerintah sehingga tidak dapat sepenuhnya didelegasikan kepada pihak swasta.

Pendanaan proyek ini berasal dari dana pemerintah dan swasta (BUMN, investor asing dan investor domestik) melalui public private partnership. Kategori ketiga adalah proyek yang secara komersial menguntungkan sehingga dapat diserahkan pengelolaannya kepada pihak swasta. Pendanaan proyek ini dapat diserahkan kepada pihak swasta melalui mekanisme direct lending sehingga tidak membebani anggaran 
pemerintah yang terbatas. Untuk itu investor perlu menghitung dengan baik tingkat pengembalian modal proyek tersebut.

Analisis kelayakan investasi daerah dapat dilakukan melalui pendekatan biaya modal (cost of capital). Menurut pendekatan ini, penyertaan modal pemerintah dapat dilakukan bila tingkat pengembalian modal (return of equity) melebihi biaya modal (cost of equity) yang dikeluarkan. Dalam hal investasi akan didanai sebagian atau seluruhnya dengan penyertaan modal maka dapat digunakan capital asset pricing model (CAPM) sebagai alat untuk mengetahui besarnya biaya modal tersebut.

CAPM yang ditemukan oleh William Sharpe pada tahun 1964 telah digunakan secara luas dalam perhitungan biaya modal oleh perusahaan terutama yang sahamnya diperdagangkan di pasar modal. Keunggulan CAPM dalam perhitungan biaya modal adalah kemampuannya untuk mengaitkan biaya modal dengan risiko usaha dalam satu persamaan model regresi linear karena model ini sejatinya diturunkan dari garis security market line. Atas keunggulannya tersebut maka William Sharpe mendapat penghargaan nobel ekonomi. Pendekatan CAPM sendiri sampai saat ini masih dipakai dalam penilaian biaya modal (Boyer et al., 2017; Raza et al., 2020; Situm, 2021)

Penelitian ini bertujuan untuk mengkaji aplikasi CAPM dalam pengambilan keputusan investasi daerah. Data yang digunakan dalam analisis ini adalah data sekunder berupa laporan keuangan dan laporan auditor independen tahun 20122017. Data dianalisis dengan kerangka analisis penganggaran modal khususnya perhitungan biaya modal dan tingkat pengembalian modal. Dalam menghitung tingkat pengembalian modal (return on equity), dilakukan analisis rasio secara runtut waktu (time series) yang dilanjutkan dengan analisis Du-Pont. Hasil penelitian ini akan dapat bermanfaat sebagai acuan model analisis kelayakan investasi pada perusahaan yang dimiliki oleh pemerintah.

Hasil analisis menunjukkan bahwa CAPM dapat digunakan untuk melakukan evaluasi investasi daerah karena melalui analisis diketahui bahwa keputusan investasi dapat dilakukan dengan membandingkan tingkat pengembalian modal yang dihitung dengan CAPM dengan imbal hasil proyek (investasi) daerah.

\section{Telaah Pustaka}

Penganggaran modal (capital budgeting) sendiri merupakan serangkaian proses mengevaluasi dan seleksi investasi jangka panjang yang sesuai dengan tujuan organisasi dalam rangka memaksimalkan kesejahteraan pemilik (Gitman \& Zutter, 2015). Dalam menyeleksi berbagai opsi investasi jangka panjang, organisasi dapat menggunakan teknik seperti Internal Rate of Return, Payback Period, dan Net Present Value. Praktik penganggaran modal akan sangat dipengaruhi oleh pengalaman manajemen/pengelola (Lima et al., 2017), lingkungan bisnis, dan perencanaan strategis organisasi (Al-Mutairi et al., 2018). Dalam konteks pemerintah, termasuk pemerintah daerah, investasi menjadi salah satu sarana untuk meningkatkan pertumbuhan ekonomi daerah (Buana et al., 2018), yang pada gilirannya akan 
bermanfaat bagi kesejahteraan masyarakat umum (Purnamasari, 2017). Perencanaan penganggaran modal oleh pemerintah yang dilakukan secara baik akan bermanfaat untuk menjaga keuangan pemerintah ketika terjadi guncangan krisis (Srithongrung, 2018).

Biaya modal merupakan ekspektasi cost of fund dari aktivitas pendanaan suatu organisasi dalam jangka panjang (Gitman \& Zutter, 2015). Aktivitas pendanaan suatu organisasi umumnya melibatkan sumber hutang dan dana milik sendiri (modal sendiri). Masing-masing sumber dana tersebut memiliki konsekuensi biaya yang spesifik. Pendanaan dari hutang akan membebani organisasi dengan biaya bunga. Demikian pula dengan modal milik sendiri, akan juga memiliki konsekuensi biaya modalnya, yang disebut dengan cost of equity. Secara khusus, cost of equity umumnya diukur dengan pendekatan Gordon growth model dan CAPM (Gitman \& Zutter, 2015). Mengingat sumber pendanaan yang merupakan kombinasi antara hutang dan modal sendiri, maka kalkulasi biaya modal selanjutnya diukur sebagai satu kesatuan struktur modal dengan pendekatan weighted average cost of capital (WACC).

Penelitian terdahulu tentang CAPM sendiri telah menemukan bahwa pendekatan CAPM dinilai lebih baik digunakan dibanding metode lain karena kesederhanaan penggunaannya (Afzal \& Haiying, 2020; Mehta \& Afzelius, 2017). Selain itu, CAPM juga dapat dijadikan metode pengambilan keputusan penganggaran modal dalam lingkungan eksternal yang dinamis, bertumbuh bahkan ketika terjadi ambiguitas informasi maupun krisis (Negrea \& Toma, 2017; Susanti et al., 2020). CAPM juga dapat dimanfaatkan untuk pengambilan keputusan terkait penganggaran modal pada berbagai jenis organisasi (Ferreira Savoia et al., 2019; Xiao et al., 2019).

\section{Metoda}

Analisis ini menggunakan data sekunder, berupa laporan keuangan dan laporan auditor independen tahun 2013-2017, serta data penunjang dari laman Aswath Damodaran (www.damodaran.com) untuk memperoleh data risiko sistematis $(\beta)$ dan risk premium Sedangkan data tingkat pengembalian bebas risiko (risk free returnrf) diperoleh dari Indonesian Bond Pricing Agency (PHEI, 2018). Objek penelitian ini adalah sebuah perusahaan milik pemerintah kota di salah satu provinsi di Pulau Jawa. Objek ini dipilih karena memiliki permodalan murni yang bersumber dari penyertaan pemerintah daerah, sehingga terdapat pengendalian penuh dari pemerintah. Kondisi ini menarik untuk diteliti, sebab analisis kelayakan investasi pada usaha yang sumber permodalannya dari pemerintah masih relatif jarang diteliti.

Dalam analisis kelayakan, digunakan kerangka analisis penganggaran modal khususnya perhitungan biaya modal dan tingkat pengembalian modal. Pendekatan biaya modal adalah pendekatan yang lebih tepat dalam menentukan kelayakan proyek pemerintah dibandingkan biaya pinjaman/cost of borrowing (Brealey et al., 1997). 
Untuk menghitung biaya modal digunakan formula Capital Asset Pricing Model (Sharpe, 1964) sebagai berikut:

Cost of capital $=$ risk free return $(\mathrm{rf})+($ risk premium $\times \beta)$

risk premium = market return-risk free return.

Dengan menggunakan data dari laporan keuangan, dilakukan perhitungan tingkat pengembalian modal (return on equity). Beberapa rasio yang dihitung tertera pada Tabel 1 sebagai berikut (Widayanti et al., 2009):

Tabel 1. Jenis Analisis Rasio

\begin{tabular}{cc}
\hline Jenis Rasio & Rumus \\
\hline Net Profit Margin & Laba Setelah Pajak / Total Penjualan \\
Total Asset Turnover & Penjualan / Total Aktiva \\
ROI & Laba Setelah Pajak / Total Aktiva \\
Equity Multiplier & Total Aset / Modal \\
ROE & Laba Setelah Pajak / Modal \\
\hline
\end{tabular}

Analisis runtut waktu dilakukan untuk rasio tersebut selama periode 2012-2017. Hasil perhitungan rasio dipetakan dalam kerangka analisis Du Pont. Keputusan kelayakan diambil dengan membandingkan tingkat pengembalian (ROE) dan biaya modal (Cost of Capital/CoC). Proyek layak dijalankan jika ROE>CoC.

\section{Hasil dan Pembahasan}

\section{Analisis Kelayakan}

\section{Perhitungan Cost of Capital (Equity)}

Sesuai dengan langkah analisis yang disampaikan dalam bagian metode, langkah pertama dalam analisis kelayakan adalah menghitung biaya modal (Cost of Capital). Untuk itu diperlukan data terkait tingkat pengembalian bebas risiko (rf), premi risiko ekuitas (risk premium) dan risiko sistematis $(\beta)$. Tabel 2 menyajikan data terkait perhitungan biaya modal pada proyek. 
Tabel 2. Elemen Biaya Modal Proyek

\begin{tabular}{|c|c|c|}
\hline Variable & Nilai & Keterangan \\
\hline $\begin{array}{c}\text { Pengembalian bebas risiko } \\
\text { (rf) }\end{array}$ & $8,50 \%$ & $\begin{array}{c}\text { Mengacu pada tingkat imbal hasil } \\
\text { obligasi pemerintah berjangka } 30 \\
\text { tahun, tanggal } 28 \text { Agustus } 2018 \text { (PHEI, } \\
\text { 2018). }\end{array}$ \\
\hline $\begin{array}{l}\text { Premi risiko ekuitas (risk } \\
\text { premium) }\end{array}$ & $7,62 \%$ & $\begin{array}{c}\text { Data total equity risk premium dari } \\
\text { laman Aswath Damodaran } \\
\text { (Damodaran, 2018). } \\
\text { Digunakan total equity karena sumber } \\
\text { dana proyek sepenuhnya dari } \\
\text { modal/equity. }\end{array}$ \\
\hline World $\beta$ (diversified) & 0,76 & $\begin{array}{c}\text { Digunakan unlevered beta karena } \\
\text { proyek tidak berhutang. Data } \\
\text { diperoleh dari laman Aswath } \\
\text { Damodaran (Damodaran, 2018). }\end{array}$ \\
\hline World $\beta$ (oil and gas) & 1,08 & $\begin{array}{l}\text { Digunakan unlevered beta untuk oil } \\
\text { dan gas karena bisnis utama proyek } \\
\text { adalah SPBU. Data diperoleh dari } \\
\text { laman Aswath Damodaran } \\
\text { (Damodaran, 2018). }\end{array}$ \\
\hline Country default spead & $2,26 \%$ & $\begin{array}{c}\text { Data country default spread dari } \\
\text { laman Aswath Damodaran } \\
\text { (Damodaran, 2018). }\end{array}$ \\
\hline \multicolumn{3}{|c|}{ Cost of Capital $_{1}=8,5 \%+7,62 \% \times 0,76-2,26 \%=12,02 \%$ (Batas Bawah) } \\
\hline \multicolumn{3}{|c|}{ Cost of Capital $2_{2}=8,5 \%+7,62 \% \times 1,08-2,26 \%$} \\
\hline
\end{tabular}

Berdasarkan analisis di atas, dapat diketahui bahwa Cost of Capital proyek berada pada kisaran 12,02\%-14,47\%. Dengan kata lain, penyertaan modal sebagai biaya modal pemerintah daerah bagi proyek daerah sebesar 12,02\%-14,47\% per tahun.

Tabel 3. Nilai Biaya Modal

\begin{tabular}{ccccccc}
\hline \multicolumn{7}{c}{ Skenario 1: Biaya Modal 12,02\% } \\
\hline & $\mathbf{2 0 1 2}$ & $\mathbf{2 0 1 3}$ & $\mathbf{2 0 1 4}$ & $\mathbf{2 0 1 5}$ & $\mathbf{2 0 1 6}$ & $\mathbf{2 0 1 7}$ \\
Modal (Juta Rp) & 5.066 & 5.045 & 5.091 & 5.167 & 5.235 & 5.231 \\
Cost of Capital (\%) & $12,02 \%$ & $12,02 \%$ & $12,02 \%$ & $12,02 \%$ & $12,02 \%$ & $12,02 \%$ \\
Cost of Capital (Juta Rp) & 608 & 606 & 612 & 621 & 629 & 628 \\
& Skenario & 2 : Biaya Modal 14,47\% & & & \\
& 2012 & 2013 & 2014 & 2015 & 2016 & 2017 \\
Modal (Juta Rp) & 5.066 & 5.045 & 5.091 & 5.167 & 5.235 & 5.231 \\
Cost of Capital (\%) & $14,47 \%$ & $14,47 \%$ & $14,47 \%$ & $14,47 \%$ & $14,47 \%$ & $14,47 \%$ \\
Cost of Capital (Juta Rp) & 733 & 730 & 737 & 748 & 758 & 757 \\
\hline
\end{tabular}

Dari analisis pada Tabel 3 di atas, dapat diketahui bahwa biaya yang sebenarnya disediakan dalam rangka mendanai usahanya (dari penyertaan modal Pemerintah Daerah), berkisar Antara 606-629 Juta Rupiah selama tahun 2012-2017 (pada biaya modal 12,02\%) dan 730-758 (pada biaya modal 14,47\%). 


\section{Perhitungan Return on Equity}

Berdasarkan data historis berupa laporan keuangan dapat disajikan informasi analisis Du Pont untuk periode tahun 2012-2017 pada Tabel 4. Berdasarkan analisis Du Pont pada Tabel 4, dapat diketahui bahwa secara aktual ROE yang berhasil dihasilkan proyek selama tahun 2012-2017 berkisar antara 0,469\% sampai dengan $2,508 \%$. ROE paling rendah terjadi pada tahun 2013, yang terutama disebabkan karena HPP yang relatif lebih tinggi dibanding tahun-tahun yang lain. Adapun ROE tertinggi terjadi pada tahun 2016, yang juga terutama dikontribusikan oleh HPP yang relatif paling rendah dibandingkan tahun-tahun lainnya. Rendahnya HPP diduga lebih disebabkan oleh faktor eksternal yaitu penurunan harga input.

Tabel 4. Analisis Du Pont Tahun 2012-2017

\begin{tabular}{ccccccc}
\hline & \multicolumn{7}{c}{ Tahun } \\
\cline { 2 - 7 } & $\mathbf{2 0 1 2}$ & $\mathbf{2 0 1 3}$ & $\mathbf{2 0 1 4}$ & $\mathbf{2 0 1 5}$ & $\mathbf{2 0 1 6}$ & $\mathbf{2 0 1 7}$ \\
\hline \multirow{2}{*}{ Elemen Laporan Keuangan (Juta Rp) } \\
Net Profit After Tax & 73 & 23 & 59 & 84 & 131 & 49 \\
Sales & 22.772 & 28.936 & 36.172 & 42.211 & 40.771 & 42.128 \\
Total Asset & 5.269 & 5.105 & 5.114 & 5.189 & 5.235 & 5.399 \\
Stockholder's Equity & 5.066 & 5.045 & 5.091 & 5.167 & 5.235 & 5.231 \\
\hline & \multicolumn{7}{c}{ Indikator Du Pont } & & \\
Net Profit Margin & $0,325 \%$ & $0,082 \%$ & $0,164 \%$ & $0,199 \%$ & $0,322 \%$ & $0,117 \%$ \\
Total Asset Turnover & 4,32 & 5,67 & 7,07 & 8,13 & 7,79 & 7,80 \\
ROI & $1,404 \%$ & $0,464 \%$ & $1,159 \%$ & $1,620 \%$ & $2,508 \%$ & $0,912 \%$ \\
Equity Multiplier & 1,04 & 1,01 & 1,00 & 1,00 & 1,00 & 1,03 \\
ROE & $1,460 \%$ & $0,469 \%$ & $1,164 \%$ & $1,627 \%$ & $2,508 \%$ & $0,941 \%$ \\
\hline
\end{tabular}

Sumber: Laporan Keuangan, diolah

\section{Analisis Biaya-Manfaat (Cost of Equity dan Return on Equity)}

Sebagaimana diuraikan dalam bagian metode, analisis biaya-manfaat dilakukan melalui perbandingan tingkat pengembalian dan biaya modal, maka berikut ini tersaji dalam Tabel 5. Berdasarkan analisis pada Tabel 5 dapat diperoleh gambaran bahwa sebenarnya dalam rangka penyertaan modal Pemerintah daerah mengorbankan biaya berkisar 606-629 Juta Rupiah pada biaya modal 12,02\% (setara dengan biaya 730-758 pada biaya $14,47 \%$ ). Namun disisi lain, manfaat yang berhasil diperoleh dari pengorbanan biaya tersebut hanya berkisar 23-131 Juta Rupiah (0,469\% - 2,508\%).

Dari gambaran tersebut dapat diketahui bahwa pengorbanan biaya yang ditanggung pemerintah daerah jauh lebih besar daripada manfaat yang berhasil diperoleh. Informasi ini memberikan makna bahwa usaha daerah dapat dikategorikan tidak sehat, yaitu ketika laba aktual tidak dapat menutup pengorbanan biaya pendanaan modal sebagai batas minimal yang seharusnya ditetapkan.

Hasil analisis mendukung pernyataan (Srithongrung, 2018) bahwa perencanaan penganggaran modal pemerintah yang dilakukan secara komprehensif bermanfaat untuk menjaga keuangan pemerintah ketika terjadi guncangan krisis. Selain itu, 
analisis mendukung penelitian terdahulu tentang CAPM yang menemukan bahwa pendekatan CAPM dinilai lebih baik digunakan dibanding metode lain karena kesederhanaan penggunaannya (Afzal \& Haiying, 2020; Mehta \& Afzelius, 2017). Selain itu, CAPM juga dapat dijadikan metode pengambilan keputusan penganggaran modal dalam lingkungan eksternal yang dinamis, bertumbuh bahkan ketika terjadi ambiguitas informasi maupun krisis (Negrea \& Toma, 2017; Susanti et al., 2020).

Tabel 5. Perbandingan Cost of Equity dan Return on Equity

\begin{tabular}{ccccccc}
\hline & \multicolumn{7}{c}{ Tahun } \\
\cline { 2 - 7 } & $\mathbf{2 0 1 2}$ & $\mathbf{2 0 1 3}$ & $\mathbf{2 0 1 4}$ & $\mathbf{2 0 1 5}$ & $\mathbf{2 0 1 6}$ & $\mathbf{2 0 1 7}$ \\
\hline Juta Rupiah & 608 & 606 & 612 & 621 & 629 & 628 \\
$\%$ & 12,02 & 12,02 & 12,02 & 12,02 & 12,02 & 12,02 \\
& 733 & 730 & 737 & 748 & 758 & 757 \\
Juta Rupiah & 14,47 & 14,47 & 14,47 & 14,47 & 14,47 & 14,47 \\
$\%$ & 73 & Return on Equity & & & \\
Juta Rupiah & 23 & 59 & 84 & 131 & 49 \\
$\%$ & 1,460 & 0,469 & 1,164 & 1,627 & 2,508 & 0,941 \\
\hline
\end{tabular}

Analisis runtut waktu menunjukkan bahwa tingkat pengembalian tertinggi terjadi pada tahun $2016(2,508 \%)$ namun capaian ini masih jauh di bawah biaya modal yang dikeluarkan (12.02\%). Hasil ini juga masih di bawah tingkat pengembalian bebas risiko (rf) sebesar 8,5\%. Karena tingkat pengembalian bebas risiko menunjukkan hasil yang diperoleh bila investor menanamkan dananya pada instrumen bebas risiko (seperti obligasi pemerintah) maka kenyataan bahwa tingkat pengembalian modal (ROE) pemerintah daerah yang tertinggi sekalipun masih jauh di bawah tingkat pengembalian bebas risiko memberikan indikasi yang kurang baik.

Dengan kata lain jika dana pemerintah daerah diinvestasikan langsung pada obligasi pemerintah yang tidak berisiko hasilnya masih lebih menguntungkan dibandingkan penyertaan modal pada unit usaha yang jauh lebih berisiko. Padahal logikanya berdasarkan prinsip high risk high return, semakin besar risiko yang harus ditanggung investor maka semakin tinggi tingkat pengembalian yang diperoleh investor. Oleh karena itu, agar penyertaan modal pemerintah daerah menjadi layak maka tingkat pengembalian (hasil usaha) proyek perlu ditingkatkan menjadi lebih dari $12.02 \%$ (lebih besar dari biaya modalnya). Untuk itu, disarankan proyek membuat rencana bisnis (business plan) yang berisi proyeksi bisnis di masa mendatang dan menunjukkan potensi imbal hasil yang lebih besar dari biaya modal $(12.02 \%)$.

\section{Pembahasan}

Penyertaan modal pemerintah harus memperoleh return sesuai dengan risiko yang ditanggung. Menurut teori keuangan, return minimal yang seharusnya diperoleh dalam suatu investasi adalah sebesar cost of capital. Oleh karena proyek yang 
dianalisis menggunakan modal sendiri 100\%, maka cost of capitalnya adalah sebesar cost of equity. Berdasarkan perhitungan, cost of equity proyek diperkirakan sebesar $12,02 \%$ sampai dengan 14,47\%. Hal ini berarti, dengan modal sebesar Rp. 5.231.688.227,- laba minimum yang seharusnya diperoleh proyek adalah Rp. 628.704.277,- (12,02\% x 5.231.688.227) sampai dengan Rp. 757.231.499,- (14,47\% x 5.231.688.227).

Dengan laba tahun 2017 hanya sebesar Rp. 49.239.825,-, maka rencana penyertaan modal menjadi tidak layak. Penyertaan ini baru dapat dipertimbangkan apabila Manajemen proyek dapat membuat turn around business plan dengan ROE yang diperoleh minimal $12,02 \% \mathrm{~s} / \mathrm{d} 14,47 \%$ dan hal ini membutuhkan perubahan strategi bisnis yang cukup signifikan, termasuk dalam hal pengelolaannya. Langkah yang selanjutnya dapat dipertimbangkan pelibatan swasta dalam pengelolaan proyek dengan tetap mempertahankan kepemilikan pemerintah dalam proyek tersebut.

Hasil analisis perhitungan biaya modal menggunakan CAPM yang menjadi dasar pengambilan keputusan investasi proyek pemerintah daerah mendukung pernyataan (Ferreira Savoia et al., 2019; Xiao et al., 2019) yang menyatakan bahwa CAPM dapat dimanfaatkan untuk pengambilan keputusan terkait penganggaran modal pada berbagai jenis organisasi, termasuk organisasi publik seperti pemerintah daerah.

\section{Simpulan}

Berdasarkan hasil analisis kelayakan, portofolio dan risiko maka dapat ditarik kesimpulan bahwa CAPM dapat digunakan dalam mengevaluasi keputusan investasi daerah. Dengan menggunakan dasar laporan keuangan dan laporan auditor 20132017, analisis kelayakan yang dilakukan melalui perbandingan biaya modal (cost of capital/equity) dan tingkat pengembalian modal (return on equity) menunjukkan kondisi yang tidak layak. Kinerja proyek selama periode tersebut belum mampu memberikan tingkat pengembalian yang lebih besar dari biaya modalnya. Rata-rata tingkat pengembalian $(0,469 \%$ - 2,508\%) masih jauh dari biaya modal (12.02-14.7\%) bahkan masih di bawah tingkat pengembalian bebas risiko (8.5\%).

Adapun masukan dari hasil penelitian yang dapat dijadikan bahan pertimbangan oleh pemerintah daerah adalah mengambil keputusan investasi berdasarkan kajian menyeluruh dengan membandingkan biaya modal dengan proyeksi hasil dari proyek tersebut. Dalam hal proyek nilai biaya modal lebih rendah dibandingkan dengan proyeksi hasil namun terdapat potensi untuk mengembangkan proyek maka proyek dapat dipertimbangkan untuk dijalankan.

Penggunaan CAPM sebagai alat evaluasi akan memberikan objektifitas penilaian yang diperlukan agar keputusan investasi yang diambil menjadi tepat. Studi ini masih terbatas pada usaha milik pemerintah yang sumber pendanaannya murni dari penyertaan pemerintah, sehingga model penelitian ini hanya berlaku pada seting bisnis yang dikendalikan secara penuh oleh pemerintah. Pengendalian mutlak oleh pemerintah memungkinkan perusahaan dapat lebih cepat merespon tuntutan pasar 
maupun para pemangku kepentingan lain. Pada faktanya, sebagian usaha milik pemerintah juga menggalang permodalan dari masyarakat umum. Hal ini menimbulkan dinamika pengendalian yang berbeda. Penelitian mendatang disarankan juga untuk meneliti pada seting perusahaan yang permodalannya berasal dari pemerintah dan masyarakat umum.

\section{Daftar Pustaka}

Afzal, F., \& Haiying, P. (2020). Evaluating the Effectiveness of CAPM and APT for Risk Measuring and Assets Pricing. Financial Risk and Management Reviews, 6(1). https://doi.org/10.18488/journal.89.2020.61.14.21

Al-Mutairi, A., Naser, K., \& Saeid, M. (2018). Capital budgeting practices by non-financial companies listed on Kuwait Stock Exchange (KSE). Cogent Economics and Finance, 6(1). https://doi.org/10.1080/23322039.2018.1468232

Boyer, B., Lim, R., \& Lyons, B. (2017). Estimating the cost of equity in emerging markets: A case study. American Journal of Management.

Brealey, R. A., Cooper, I. A., \& Habib, M. A. (1997). Investment appraisal in the public sector. Oxford Review of Economic Policy, 13(4).

Buana, A. L., Saragih, H. J. R., \& Aritonang, S. (2018). Pengaruh Pengeluaran Pemerintah, Investasi Pemerintah,Investasi Swasta Dan Tenaga Kerja Terhadap Pertumbuhan Ekonomi Di Pulau Jawa Tahun 2011-2015. Jurnal Ekonomi Pertahanan, 4(2).

Damodaran, A. (2018). Equity Risk Premium. http://people.stern.nyu.edu/adamodar/New_Home_Page/home.htm

Ferreira Savoia, J. R., Securato, J. R., Bergmann, D. R., \& Lopes da Silva, F. (2019). Comparing results of the implied cost of capital and capital asset pricing models for infrastructure firms in Brazil. Utilities Policy, 56. https://doi.org/10.1016/j.jup.2018.12.004

Gitman, L. J., \& Zutter, C. J. (2015). Principles of Managerial Finance 14th Edition. In Pearson Education.

Lima, A. C., Da Silveira, J. A. G., Matos, F. R. N., \& Xavier, A. M. (2017). A qualitative analysis of capital budgeting in cotton ginning plants. Qualitative Research in Accounting and Management, 14(3). https://doi.org/10.1108/QRAM-07-2016-0055

Mehta, S., \& Afzelius, D. (2017). Gotta CAPM' All: An Empirical Study on the Validity of the CAPM Against Four Unique Assets. SSRN Electronic Journal. https://doi.org/10.2139/ssrn.2995585

Negrea, B., \& Toma, M. (2017). Dynamic CAPM under ambiguity—An experimental approach. Journal of Behavioral and Experimental Finance, 16. https://doi.org/10.1016/j.jbef.2017.09.001

PHEI. (2018). Indonesia Bond Indexes. http://www.ibpa.co.id/DataPasarSuratUtang/Indeks/INDOBeX/tabid/197/languag e/Default.aspx/Default.aspx

Purnamasari, F. (2017). Pertumbuhan Ekonomi: Investasi Pemerintah dan Manajemen Investasi dalam Perspektif Islam (Studi Di Kabupaten/Kota Provinsi Lampung). Jurnal Manajemen Indonesia, 17(1). Https://Doi.Org/10.25124/Jmi.V17i1.859 
Raza, H., Hashmi, A. M., \& Rasheed, A. (2020). On the Estimation of Cost of Equity using Industrial CAPM Approach. NICE Research Journal. https://doi.org/10.51239/nrjss.v0i0.176

Sinaga, H. (2018). Pendanaan Infrastruktur. KOMPAS. https://www.kompas.id/baca/opini/2018/08/27/pendanaan-infrastruktur/

Situm, M. (2021). Determination of expected cost of equity with the CAPM: Theoretical extension using the law of error propagation. Managerial and Decision Economics, 42(1). https://doi.org/10.1002/mde.3214

Srithongrung, A. (2018). Capital Budgeting and Management Practices: Smoothing Out Rough Spots in Government Outlays. Public Budgeting and Finance, 38(1). https://doi.org/10.1111/pbaf.12167

Susanti, E., Ernest Grace, \& Nelly Ervina. (2020). The Investing Decisions during the COVID-19 Pandemic by Using the Capital Asset Pricing Model (CAPM) Method in LQ 45 Index Companies. International Journal of Science, Technology \& Management, 1(4). https://doi.org/10.46729/ijstm.v1i4.66

Widayanti, R., Ekawati, H., Atahau, A. D. R., Rita, M. R., \& Sucahyo, U. S. (2009). Manajemen Keuangan. FE UKSW.

Xiao, Z., Yang, Y., Li, L., \& Zhong, Y. (2019). Empirical Test of the Effectiveness of CAPM for Shanghai Stock Market-Based on Industry Grouping. https://doi.org/10.2991/febm19.2019.24 